Article

\title{
Asymmetry of Risk Evolution in Crude Oil Market: From the Perspective of Dual Attributes of Oil
}

\author{
Yanqiong Liu ${ }^{1}$, Zhenghui $\mathrm{Li}^{2, *(\mathbb{D}}$, Yanyan Yao ${ }^{3}$ and Hao Dong ${ }^{4}(\mathbb{D}$ \\ 1 Business School, Hunan First Normal University, Changsha 410205, China; sxyliuyq@hnfnu.edu.cn \\ 2 Guangzhou Institute of International Finance, Guangzhou University, Guangzhou 510405, China \\ 3 Accounting Office, Guangzhou Municipal Finance Bureau, Guangzhou 510623, China; \\ 1111215002@e.gzhu.edu.cn \\ 4 School of Economics and Statistics, Guangzhou University, Guangzhou 510006, China; \\ donghao@e.gzhu.edu.cn \\ * Correspondence: lizh@gzhu.edu.cn; Tel.: +86-1335-285-7358
}

Citation: Liu, Y.; Li, Z.; Yao, Y.; Dong, H. Asymmetry of Risk Evolution in Crude Oil Market: From the

Perspective of Dual Attributes of Oil.

Energies 2021, 14, 4063. https://

doi.org/10.3390/en14134063

Academic Editor: Susan Krumdieck

Received: 17 May 2021

Accepted: 2 July 2021

Published: 5 July 2021

Publisher's Note: MDPI stays neutral with regard to jurisdictional claims in published maps and institutional affiliations.

Copyright: (C) 2021 by the authors. Licensee MDPI, Basel, Switzerland. This article is an open access article distributed under the terms and conditions of the Creative Commons Attribution (CC BY) license (https:/ / creativecommons.org/licenses/by/ $4.0 /)$.

\begin{abstract}
Investor emotional heterogeneity and oil dual attributes are the key factors that cause the asymmetry of risks in the international crude oil market. This paper uses the monthly data from April 2003 to October 2020 to identify the dynamic characteristics of oil's commodity attribute and financial attribute, and this paper also analyzes the asymmetric characteristics of risk evolution and risk degree in the international crude oil market under the condition of oil returns heterogeneity. The empirical results show that: first, there is heterogeneity in the influence of oil attributes on the risk evolution and risk degree of the international crude oil market; second, the alternation of oil dual attributes has a significant asymmetric impact on the risk evolution of international crude oil market; third, the sudden change of international crude oil market risk caused by oil attributes is asymmetric under different oil returns trends. Based on the empirical conclusion, this paper puts forward the corresponding policy recommendations.
\end{abstract}

Keywords: risk evolution of international crude oil market; the rising and falling trend of returns; CAViaR; asymmetry

\section{Introduction}

The commodity and financial attributes of oil aggravate the uncertainty of international crude oil market returns. As the most financialized energy product, oil has not only commodity attributes, but also financial attributes. Global capital flows and investor speculation increase the uncertainty of risk evolution in the international crude oil market [1-6]. The evolution of crude oil risk has a significant correlation with crude oil price and returns. The establishment of oil finance attributes has attracted international investors, especially funds and other institutions to enter the international crude oil market. According to the U.S. Energy Information Administration (EIA) report, the number of trading contracts in the crude oil futures market in January 2008 is 49,120 . The largest number of transactions is 482,780 in January 2018. In November 2020, the contract volume of the crude oil futures market is 330,100 . The number of investors in the international crude oil market is highly correlated with the evolution of crude oil spot prices and returns (as shown in Figure 1). On the one hand, the price of the crude oil futures market has a leading role in the international crude oil spot market [7]. In the context of oil financialization, crude oil futures prices are affected by supply and demand fundamentals and external factors such as emergencies, policy uncertainty and war [8]. With the development of the information revolution and the wide application of information technology, investors' ability to obtain information is enhanced, and then investors' expectations are more vulnerable, thus changing the decision of market participants in the crude oil futures market and finally affecting the national crude oil market contract transactions. On the other hand, the risk of the international 
crude oil market is related to the changing degree of market returns [9-11]. It can be seen from Figure 1 that the changing degree of returns in the international crude oil market is the same as that in the crude oil futures market. Specifically, at the end of 2008, the net trading volume of contracts in the crude oil futures market is negative, and the international crude oil market returns fluctuate greatly. When the net contract volume in the crude oil futures market is high, the volatility of crude oil returns is also relatively stable (From February to June in 2014 and from December 2017 to September 2018). In early 2020, affected by external circumstances such as wars and epidemics, crude oil futures market contract volume fell from 300,780 to 134,430 , then gradually rebounded to 374,810 . The change of trading volume makes the international crude oil market returns experience a "roller coaster" ride. In addition, the development of alternative energy in recent years provides greater uncertainty for crude oil demand. Therefore, the risk evolution of the international crude oil market has dynamic characteristics.

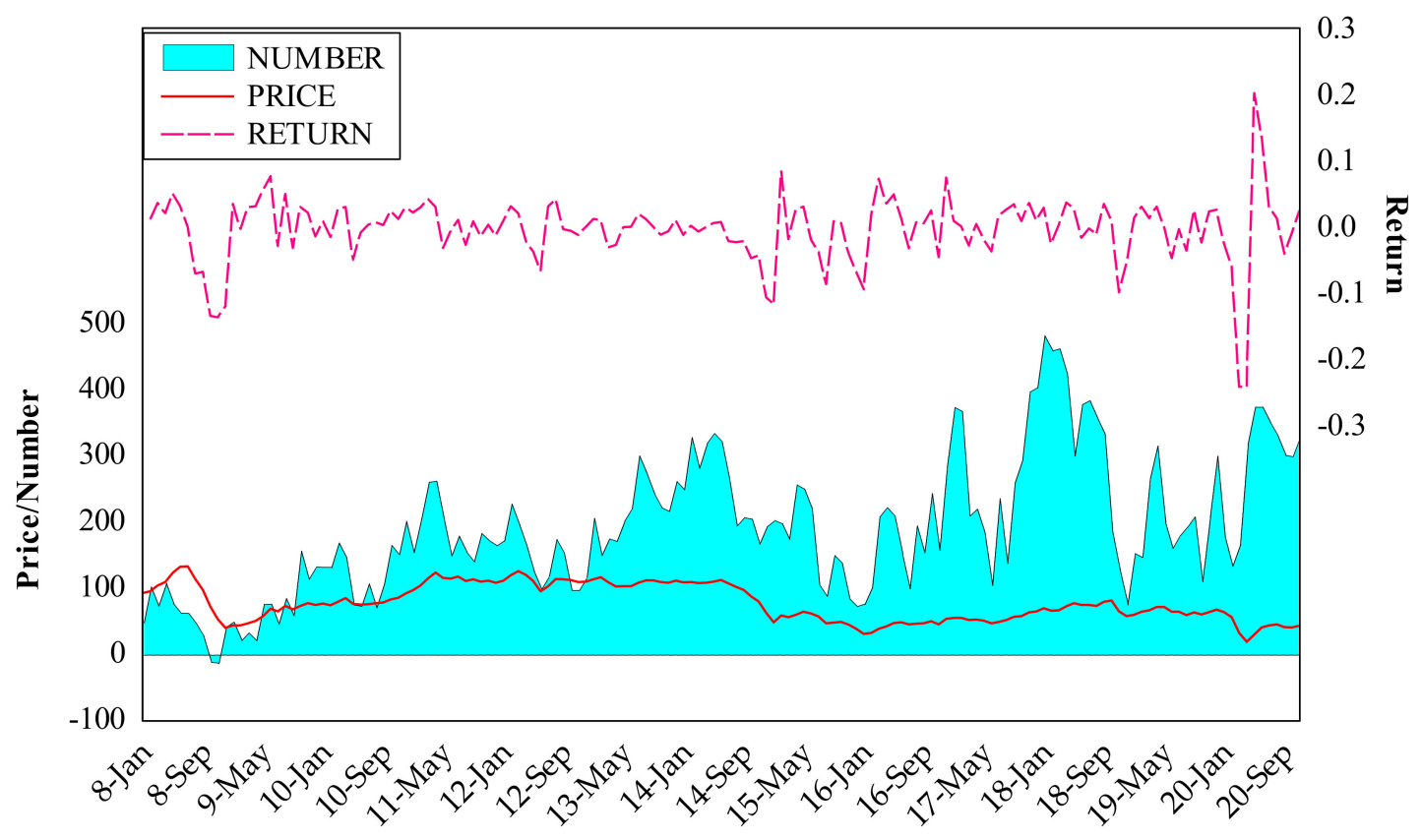

Figure 1. Trading volume of crude oil futures market and crude oil spot price and returns.

Under the condition of returns heterogeneity, the risk evolution characteristics of the international crude oil market are asymmetric. The asymmetry of international crude oil market risk is mainly related to the heterogeneity of market returns in the face of information shock and the difference of investors' expectations under different returns trends [12]. On the one hand, the heterogeneity of information shock is reflected in the leverage effect of market returns [13]. Specifically, the impact of negative information on market returns will produce greater returns fluctuations. On the other hand, when the market returns rise or fall, investors have different judgments on the expected average returns of the market. This difference will make investors adjust their capital allocation strategy, and then affect the uncertainty of market returns [14-16].

The main purpose of this paper is to analyze the asymmetric characteristics of the risk evolution in the international crude oil market under the condition of returns heterogeneity. The analysis of the risk evolution characteristics of the international crude oil market under the dual attributes of oil is conducive to the prevention and emergency work before crisis, so as to formulate timely coping strategies, reduce the impact of international crude oil price fluctuations on investors' returns, financial system and economic development, and further improve the financial market security network to ensure the smooth and sustainable development of the economy. In addition, when risks occur in the international crude oil 
market, they can be spread quickly through information, investors' expectations, capital flows and other channels. The high degree of markets relevance makes risks spillover from the crude oil market to other markets, leading to the "domino effect" in multiple markets. Further, due to the heterogeneity of information acquisition between investors and speculators, there are differences in the ability of investors and speculators to respond to market price fluctuations under different trends. By analyzing the heterogeneity of oil market spillover effect and spillover mechanism under different trends, this paper provides an empirical basis for preventing risk contagion caused by speculators' behavior and protecting the legitimate rights and interests of investors. It is beneficial to arrange the policies under different returns trends, perfect the information-sharing mechanism across markets, and fundamentally guard against the negative impact of the price fluctuation of the international crude oil market on the commodity market, financial market and economic development.

The measurement method of asset price risks is one of the key topics concerned by scholars $[15,17,18]$. According to the nature of asset price returns and risks, existing literature on risk measurement methods mainly includes two aspects. First, based on the heteroscedasticity of asset price returns, the Value at Risk (VaR) method is the most widely used. Cabedo and Moya [19] assumed heteroscedasticity of crude oil returns and measured the risk of the crude oil market based on the GARCH model. Thereafter, most of the literature adopts static and dynamic VaR based on the GARCH model to predict financial market risks in stock markets, international crude oil markets and virtual currency markets [20-23]. For example, based on the heteroscedasticity of virtual currency returns, Li et al. [24] measured virtual currency market risks with different types of GARCH models. They found that the GARCH model based on normal distribution can better predict the risk of the virtual currency market, and they also found that the fluctuation of risk and returns in the virtual currency market had a strong correlation. In view of the situation that the VaR method cannot measure the probability of higher risks, the extreme theory was proposed by Longin [25] who used the generalized extremum distribution to study the risk of the stock market and got better prediction results. Additionally, Zhao et al. [26] forecasted the oil risks based on fractional GARCH models, in which they took account for long memory, volatility clustering, asymmetric and thick tails. Yang and Hamori [27] proposed a wavelet-based semiparametric model to perform a VaR forecast and expected shortfall. Valenti et al. [28] predicted the oil risk premium based on a regression model which includes economic activities.

The second is to measure asset price risk based on its aggregation feature and the difference of the impact of different types of returns on the risk. Engle and Manganeli [29] proposed a conditional autoregressive VAR model (CAViaR) based on the quantile regression theory according to the agglomeration of asset returns. This model, which has become an important method of quantile modeling, describes the dynamic change characteristics of VaR, accurately describes the risk autoregression and the impact of market shock on the returns rate [15,30-32]. Dong et al. [14] used four forms of the CAViaR model to measure crude oil market risks and found that the asymmetric CAViaR model can better predict crude oil market risks, indicating that positive and negative returns of crude oil market have a strong asymmetric impact on risks. In addition, Yousesef et al. [33] predicted crude oil market risks based on the properties of asymmetry, heterogeneity and thick tail of the crude oil market. The results show that these properties can better predict the high volatility energy market risk. Jeon and Taylor [34] built a CAViaR model based on implied volatility to predict the market risk of the S\&P 500. Drako et al. [35] considered the impact of the financial crisis on the risks of the international stock market around 2007-2009. Qureshi [36] adopted the CAViaR model to measure the risks caused by positive and negative returns in international stock markets during the periods of 1986-1999 and 1999-2009, respectively. Meng and Taylor [32] employed the CAViaR model with long memory to forecast the risks of 18 markets based on daily trading data. Compared with other types of CAViaR models, the research results show that the model based on daily trading data can better identify 
the agglomeration characteristics of 18 market risks, and then better predict market risks. Wen et al. [37] employed the VAR for VaR framework including the MVMQ-CAViaR model and the pseudo QIRF to investigate the risk spillover effect between crude oil and foreign rate exchange markets.

Existing literature provides a certain basis for the measurement of international crude oil market risk and spillover effects, as well as the following further research space. First, the dominant period of oil dual attributes needs to be further identified. The formation mechanism of different oil attributes has changed the structure of international crude oil market participants and further affected the heterogeneity of international crude oil market price and returns. Second, the heterogeneity of the risk evolution of the international crude oil market in different oil-attributed dominant periods needs to be analyzed. According to the relevant literature on the risk measurement of the international crude oil market, different research methods get different characteristics of risk evolution in the international crude oil market, mainly considering the impact of the external environment on the risks of the international crude oil market, such as financial crises, tsunamis, earthquakes and OPEC decisions. In the dominant period of the commodity attribute of oil, the risk evolution of the international crude oil market will be mainly affected by the relationship between supply and demand; while in the dominant period of the financial attribute of oil, the risk evolution of international crude oil market is mainly affected by monetary policy and investors' expectations. Therefore, both the commodity and financial attributes of oil will affect the risk evolution of the international crude oil market. Compared with the commodity attribute oil, the financial attribute of oil has a more intense influence on the risk evolution of the crude oil market, causing stronger risk fluctuation.

The overall framework of this paper is as follows: the second section is about the dynamic feature identification of oil dual attributes, which provides the basis for sample division to analyze the stage and asymmetry of risk evolution; the third section is the selection of risk measurement methods; the fourth section is the empirical analysis. The main conclusions of this paper are in the fifth section.

\section{Oil Dual Attributes Identification}

\subsection{Definition and Identification of Dual Attributes of Oil}

The financial attribute of oil is highly related to the financialization of the international crude oil market. The development of oil financial derivatives such as crude oil futures has become the main force to promote the financialization of the international crude oil market. The international crude oil market and financial market have been closely combined. Oil can no longer be simply regarded as a commodity, but a composite commodity with the characteristics of financial products [38]. Specifically, the shortening of the period of price fluctuation and the increase of fluctuation range in the international crude oil market are the manifestations of oil financial attributes [39]. Secondly, the development of the oil derivatives financial market, such as markets of international crude oil futures, oil options, forward and swap, makes oil price indexation gradually. The pricing power of crude oil has not only become the strategic goal of national and regional competition, but also the key indicator of investors' judgment of market information [40-42]. In addition, the inflow of financial assets into the international crude oil market increases the volatility and risk of oil prices. At the same time, considering the negative relationship between the international crude oil market and the financial market, the price fluctuation and risk not only reflect changes in investors' expectations, but also be infected by the risk of the financial market. Based on this, this paper defines the financial attribute of oil as: the formation and fluctuation of international crude oil market prices have the basic characteristics of financial products and can play a role in the financial market. In essence, the financial attribute of oil refers to the use of various oil financial derivatives by oil investment groups, driven by the dollar exchange rate, crude oil speculation and other financial factors, so that international crude oil prices reflect more the will of financial institutions such as speculative groups. 
The financial attribute of oil determines that the price of the international crude oil market is positively affected by monetary policy. On the one hand, monetary policy is a key factor for the dollar exchange rate to influence or even manipulate international oil prices $[40,41]$. On the other hand, monetary policy creates opportunities for hedgers and speculators to profit from the international crude oil market. The impact of monetary policy on international crude oil market prices is mainly due to changes in speculative demand $[39,43]$. As a demand regulation policy, expansionary monetary policy will increase the demand for oil, reduce the uncertainty of the international crude oil market, and release good news for investors. Investors' mastery of the news enhances their optimistic expectations, and then changes the allocation of investors' funds in real investment and financial investment, and the speculative demand increases accordingly [44]. Therefore, good news leads to the rise in the price of oil financial derivatives, and ultimately affects the spot price of the international crude oil market. On the contrary, tightening monetary policy increases the uncertainty of investment in the international crude oil market, which leads to the change of investors' expectations and the decline of speculative demand, resulting in the decline of oil financial derivatives prices [45]. Due to the important role of oil financial derivatives in price discovery, hedging and risk aversion, the spot price of the international crude oil market has also changed accordingly.

Based on the above analysis, this paper puts forward the basic hypothesis of oil financial attribute identification

Hypothesis 1 (H1). The financial attribute of oil is related to the positive impact of monetary policy on international crude oil prices.

The particularity of oil commodity determines its commodity attribute. As a key input commodity in production activities, oil has three remarkable characteristics besides the characteristics of general commodities. The first characteristic is scarcity. Oil is a kind of non-renewable energy, which has certain restrictions on exploitation and storage. Due to the fact that oil is not enough to meet the long-term dependence of human development on oil, so the primary characteristic of oil is scarcity. At the same time, the increasing dependence of economic development on oil increases the demand for oil and further affects the oil supply. Second, oil has a strategic characteristic. As the most important input factor, oil has penetrated into different fields of economic development, so the dependence of economic development on oil is formed, and this dependence varies in different stages of the economic cycle. Therefore, different countries and regions regard the control of different links of oil as an important strategy. Third, oil has a political feature. The uneven distribution of oil supply and the difference in oil demand among countries and regions determine that oil has political characteristics. In particular, the reserves and production of oil resources are concentrated in the Middle East, Africa, South America and Canada. On the contrary, countries with high oil demand have no regional aggregation characteristics, including developed countries such as the United States, Europe and Japan, and developing countries such as China and India. This uneven global distribution of oil supply and demand has made oil political. Based on this, this paper defines the commodity attribute of oil as: the change of oil price is affected by the change of the market's supply and demand relationship to a certain extent. In essence, the commodity attribute of oil refers to that the international crude oil price gradually reflects the characteristics of production cost and supply-demand balance conversion, which are affected by the oil use cost of enterprises, oil production capacity, national oil demand and energy strategic reserves.

The identification of oil's commodity attribute is related to the positive impact of crude oil demand on international crude oil market price. The supply structure of the international crude oil market has evolved from the original OPEC countries as the main body to the present OPEC rich countries group, OPEC poor countries group and non-OPEC countries three main bodies $[15,46]$. Based on this supply structure, OPEC combined with market demand to further put forward the oil price range pricing mechanism. Yet because of differences in oil production reserves, idle capacity, and extraction costs within OPEC 
countries, OPEC not being a cartel, they can only act as recipients rather than setters of international oil prices [47]. In reality, the scarcity of oil determines the high uncertainty of oil reserves in the future. Supply is inelastic in the short term, and OPEC has a lag effect on the regulation of oil supply, so the international crude oil market price is affected by demand in the short term $[46,48]$. The demand for crude oil is usually correlated with the total demand of the national economy. When the economy is in a boom, crude oil demand increases with the increase of total social demand. At this time, the price of the international crude oil market will inevitably rise, under the condition of constant supply in the short term. Conversely, when the economy is in a depression, the total social demand is weak and the demand for oil decreases, which will reduce the price of the international crude oil market $[49,50]$. In the long run, the supply of crude oil is more elastic. However, as oil is a non-renewable resource, the storage capacity, resource endowment, production cost, production capacity and OPEC's decision will limit the supply of crude oil [48]. To sum up, in the long term, the price change of the international crude oil market is also mainly affected by the positive impact of oil demand.

Based on the above analysis, this paper puts forward the basic hypothesis of oil commodity attribute identification:

Hypothesis 2 (H2). The commodity attribute of oil is related to the positive impact of oil demand on international crude oil price.

\subsection{Model Selection of the Oil Dual Attributes Identification}

There is an endogenous relationship between international crude oil market price and monetary policy as well as oil demand. First, the above analysis made it clear that monetary policy and oil demand have positive impacts on the international crude oil price. Second, the change of international oil price will change the production cost of enterprises, and then make the oil demand change. Changes in international oil prices will also affect a country's inflation level. As one of the objectives of monetary policy, in order to maintain price stability, the country will formulate corresponding monetary policy to adjust the inflation level, so the price of the international crude oil market will also affect monetary policy [9]. Therefore, there is an endogenous relationship between international crude oil market price and monetary policy as well as oil demand, which cannot be fully described by traditional linear models. Hence, this paper considers building a series of VAR models. Moreover, taking into account the immediate impact of international crude oil price, oil demand and monetary policy, as well as the description of structural shocks on the correlation, this paper attempts to construct the SVAR model to identify the dual attributes of oil by imitating the practice of Kilian [51].

A basic form of the SVAR (p) model is constructed as Equation (1):

$$
\mathbf{B}_{0} \mathbf{X}_{\mathbf{t}}=\sum_{\mathbf{i}=1}^{\mathrm{p}} \mathbf{B}_{\mathbf{i}} \mathbf{X}_{\mathbf{t}-\mathbf{i}}+\varepsilon_{\mathbf{t}}
$$

where $X_{t}=\left(\right.$ opi $_{t}$, dem $\left._{t}, \mathrm{mpo}_{t}\right) /$ is a $3 \times 3$ vector; opi $i_{t}$ is the international crude oil market price at time $t ; d m_{t}$ refers to the oil demand at time $t ; \mathrm{mpo}_{t}$ represents the monetary policy at time $t ; p$ is the lag order, identified by the SC criterion; $\mathbf{B}_{0}$ describes the immediate impact between international crude oil market price, oil demand as well as monetary policy, and $\mathbf{B}_{\mathbf{i}}$ describes the marginal impact of lagging order $\mathrm{i}$ in the same way.

Since $\mathbf{B}_{0}$ is reversible, Equation (1) can be simplified to Equation (2):

$$
\mathbf{X}_{\mathbf{t}}=\sum_{\mathrm{i}=1}^{\mathrm{p}} \mathbf{B}_{0}^{-1} \mathbf{B}_{\mathbf{i}} \mathbf{X}_{\mathbf{t}-\mathbf{i}}+\mathbf{B}_{0}^{-1} \varepsilon_{\mathbf{t}}
$$


where $\varepsilon_{\mathrm{t}}=\left(\varepsilon_{\mathrm{t}}^{\text {price-shock }}, \varepsilon_{\mathrm{t}}^{\text {demand-shock }}, \varepsilon_{\mathrm{t}}^{\text {policy-shock }}\right) \prime$ is the structural vector of shocks on international oil price, including the specific oil price shock, the demand shock and the monetary policy shock.

Combined with the purpose of this paper and the existing literature, this paper imposes short-term zero constraints on the immediate impact matrix $\mathbf{B}_{0}$ and constructs the SVAR model. Specific constraint matrix is shown in (3):

$$
\mathbf{B}_{0} \mathbf{X}_{\mathbf{t}}=\left[\begin{array}{ccc}
1 & \mathrm{~b}_{12} & \mathrm{~b}_{13} \\
0 & 1 & \mathrm{~b}_{23} \\
0 & 0 & 1
\end{array}\right]\left[\begin{array}{c}
\mathrm{opi}_{\mathrm{t}} \\
\mathrm{dem}_{\mathrm{t}} \\
\mathrm{mpo}_{\mathrm{t}}
\end{array}\right]
$$

The corresponding position in the matrix represents the immediate impact between variables. Specifically, international crude oil price responds to oil demand and monetary policy shocks, so except that the first element in the first row of the constraint matrix is 1 , the other elements are not 0 . Although oil is the main raw material and fuel in global economic activities, yet when oil prices change, the impulse of oil demand to international crude oil price lags behind due to enterprise investment planning and oil reserves, that is, oil price shocks do not affect current oil demand, $b_{21}=0$. In addition, changes in international oil prices and oil demand will not cause changes in monetary policy, i.e., $b_{31}=b_{32}=0$, while the change of monetary policy will cause the change of oil demand in the current period.

The variables in this paper include three variables of international crude oil market price, oil demand and monetary policy. This paper uses Brent oil spot price as a proxy variable of international crude oil market price. The change of spot price of Brent and WTI crude oil can reflect the evolution characteristics of international crude oil market price. Since 2011, with the change of crude oil market mining costs, idle capacity and other factors, the international crude oil industry has gradually shifted to Western Europe, and Brent also gradually surpassed the WTI market to become the benchmark of the international crude oil market. Thus, this paper selects the spot price of Brent to measure the international crude oil price.

Oil demand is measured by the growth rate of the Baltic dry bulk freight index (BDI). The change of oil demand is highly related to economic demand, and the demand for oil increases during the economic boom, and then the price of the international crude oil market shows an upward trend, whereas the demand for oil decreases during the economic depression. Therefore, two problems should be considered in the selection of the oil demand measurement index. First, the difference in the industrial structure of different countries makes the dependence of economic development on oil different from each other. Second, the contribution of emerging countries such as BRICS in global economic development makes oil demand a key factor affecting the price change of the international crude oil market. By imitating Kilian [51] and considering the close relationship between the shipping index and oil demand, this paper selects the BDI as the proxy variable of oil demand.

This paper selects the global money supply to measure monetary policy. Based on the availability of data, this paper uses the sum of money supply in three countries or regions, i.e., the United States, Japan and the European Union, to quantify the global money supply. All the above data are from the Wind database. After acquiring the money supply of each country, we use the historical bilateral exchange rate data to convert them into US dollars and then aggregate them, and finally get the value of the monetary policy proxy variable. Monthly data from April 2003 to October 2020 are adopted in this empirical analysis. Central Bank of Japan first announced money supply M2 in April 2003. Although the time duration is short, yet the result can reflect the dynamic characteristics of the dominant oil attribute. In addition, considering the seasonal effects of variables, this paper employs X12 to adjust international crude oil price, BDI and money supply (GM2) seasonally. To eliminate heteroscedasticity, this paper further implements logarithmic processing for data. 


\subsection{Dynamic Characteristics Analysis of Dual Attributes of Oil}

Based on the model test results (see Appendix A), this paper uses first-order differential variables of Brent, BDI and GM2 to fit the SVAR model (1) to identify the dynamic characteristics of different attributes of oil. According to the basic hypotheses, the dynamic identification of oil dual attributes mainly includes two aspects: one is to identify the existence of oil commodity and financial attributes; two is to identify the dynamic characteristics of oil dual attributes. Based on this, this part first analyzes the existence of oil commodity and financial attributes with the impulse test, and finally analyzes their dynamic characteristics according to the correlation between structural shocks.

As can be seen from Figure 2, crude oil demand and money supply have a significant positive impact on international crude oil market price. Figure 2 displays the impulse response of international crude oil market price to crude oil demand (BDI) and monetary policy (M2) respectively. Figure 2a is the impulse response of the change of crude oil demand to the international crude oil market price, and Figure $2 b$ is the impulse response of the change of money supply to the international crude oil market price, indicating that the positive impact of crude oil demand and monetary policy on international crude oil price shows the existence of oil commodity attribute and financial attribute. Specifically, the impact of crude oil demand and monetary policy on the international crude oil price is positive, and this positive impact reaches the maximum when the lag period is 2 , and the impact is basically zero when the lag period is 5 . On the one hand, these results show that oil has dual attributes of commodity and finance. According to Hypothesis 1, the financial attribute of oil is related to the positive impact of monetary policy. This is mainly because the change of monetary policy will affect the driving role of financial factors such as US dollar exchange rate and crude oil asset speculation in the change of international crude oil price, thus forming the financial attribute of oil $[38,40]$.

Response of oil price to BDI

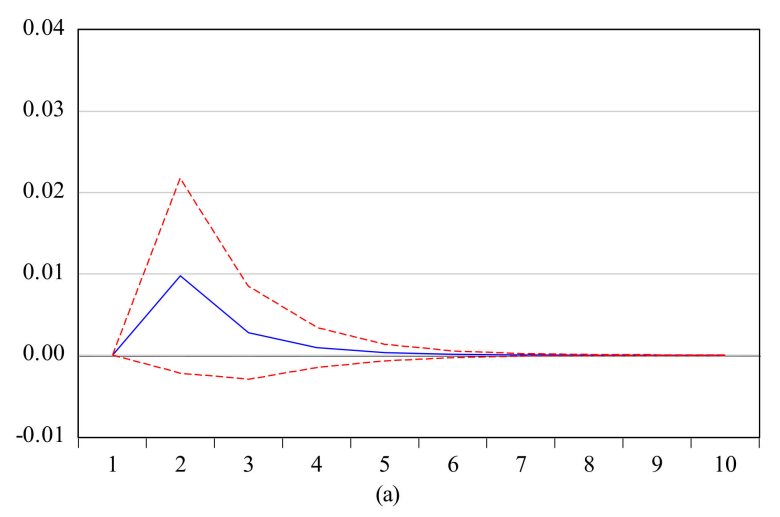

Response of oil price to M2

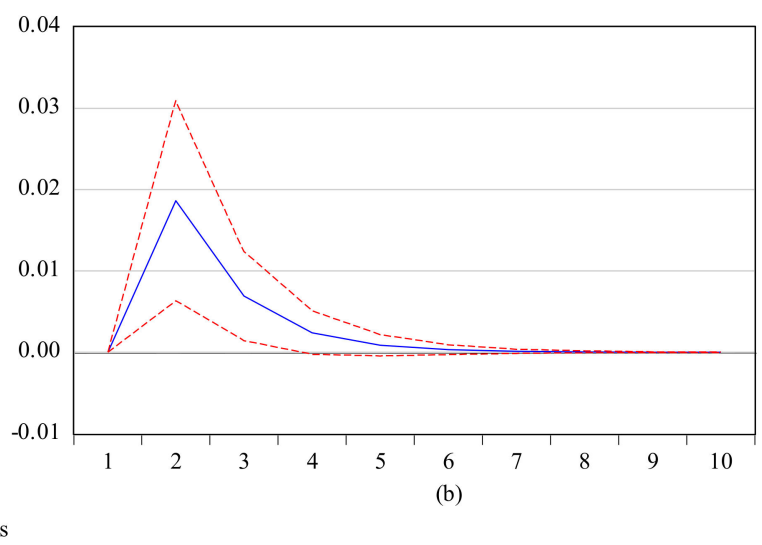

Figure 2. Identification of oil commodity attribute and financial attribute. Notes: (a) refers to the identification of oil's commercial attribute, and (b) is the identification of oil's financial attribute.

The commodity attribute of oil is related to the positive impact of crude oil demand. The evolution of the supply structure of the oil market, from the original OPEC countries as the main body to the present three main bodies of OPEC rich countries, OPEC poor countries and non-OPEC countries, has affected the supply of crude oil and weakened the pricing power of OPEC on the international crude oil market [47]. Affected by factors such as alternative energy, if oil prices are expected to rise, or future technological progress is expected to improve production efficiency and reduce production costs, oil-producing countries may delay oil production or reduce the existing production scale. The difference of long-term and short-term effects of supply and demand elasticity on international crude oil price also makes crude oil demand a key factor in international oil price fluctuation. Oil reserves always change with oil exploration activities around the world, which leads 
to uncertainty in future oil reserves. As a result, the supply is inelastic in the short term, and the adjustment of OPEC oil supply has a lag effect, so the international crude oil market price is affected by the demand in the short term. In the long run, crude oil supply elasticity is relatively large, but since oil is a non-renewable resource, its storage capacity, resource endowment, exploitation cost, extraction capacity and OPEC resolution will limit the supply of crude oil $[9,10]$. Therefore, in the long run, the price change of the international crude oil market is mainly affected by the demand for oil. In conclusion, Hypotheses 1 and 2 hold.

On the other hand, the responses of the international crude oil market to changes in oil demand and monetary policy are similar, and the similarity is related to the source of the shock. The impact of crude oil demand on the international crude oil market price is mainly affected by the external environmental changes such as technological progress, economic development and alternative energy; while the impact of monetary policy on the international crude oil market is mainly highly related to the external environment such as exchange rate fluctuations, capital flows, investor expectations and speculation [45,52]. This similarity not only illustrates the dynamic characteristics of oil dual attributes, but also indicates the importance of using the correlation between structural shocks to judge the dynamic characteristics. Under the influence of uncertain factors such as technological progress and financial market investment, entity enterprises and oil investment groups will adjust their investment strategies according to the changes of external environment to ensure their expected profits, leading to the alternation of the dominant periods of oil commercial attribute and financial attribute in the formation of international crude oil price. However, since they are all positive shocks with different impact scales, structural shocks can better describe the main roles of different variables in the market, and the correlation direction of structural shocks indicates the contribution of crude oil demand or monetary policy to the price changes in the international crude oil market. Therefore, this part further analyzes the dynamic alternation characteristics of oil commodity attributes and financial attributes.

The dominant position of oil commodity attribute and financial attribute has dynamic characteristics. Figures 3 and 4 show the dynamic feature identification of oil commodity and financial attributes, respectively. In this paper, the identification is from two aspects. On the one hand, it can be seen that crude oil demand and the structural shock of crude oil price basically change in the same direction, except for the periods of 2006M07-2007M03, 2011M12-2013M04, 2015M05-2015M12, 2019M02-2019M09, and 2020M01-2020M06. Monetary policy and the structural shock of crude oil price also change in the same direction, except for the periods of 2004M01-2006M09, 2018M09-2019M02, 2020M01-2020M07. On the other hand, in order to further compare and analyze the dynamic characteristics of the dual attributes of oil in the sample period except for the above-mentioned periods, this paper identifies whether the changing direction is positive or negative. For example, in the second half of 2003, there is a positive relationship between the shock of crude oil price and the shock of crude oil demand, so is the relationship between the shock of monetary policy and the shock of crude oil price, but the shock of monetary policy on the international crude oil price is lagging behind. This shows that the change of international crude oil price is mainly affected by the spot demand of oil, while the influence of monetary policy is lagging behind, that is, the fluctuation of international crude oil price is mainly regulated by the relationship between market supply and demand. Therefore, at this time, the oil commodity attribute dominates. From the second half of 2007 to the beginning of 2008, although the oil demand shock is positively related to the international crude oil market price shock, the shock direction is negative, while the monetary policy shock is positively related to the international crude oil market price shock, and the shock direction is positive. This indicates that the financialization of commodity markets has gradually formed, and a large amount of oil has entered the reserve field as investment or even speculation instead of entering the production field. Therefore, the oil financial attribute occupies the dominant 
position at this time. The same happened since July 2020. To sum up, this paper obtains the stage characteristics dominated by the dual attributes of oil as shown in Table 1.

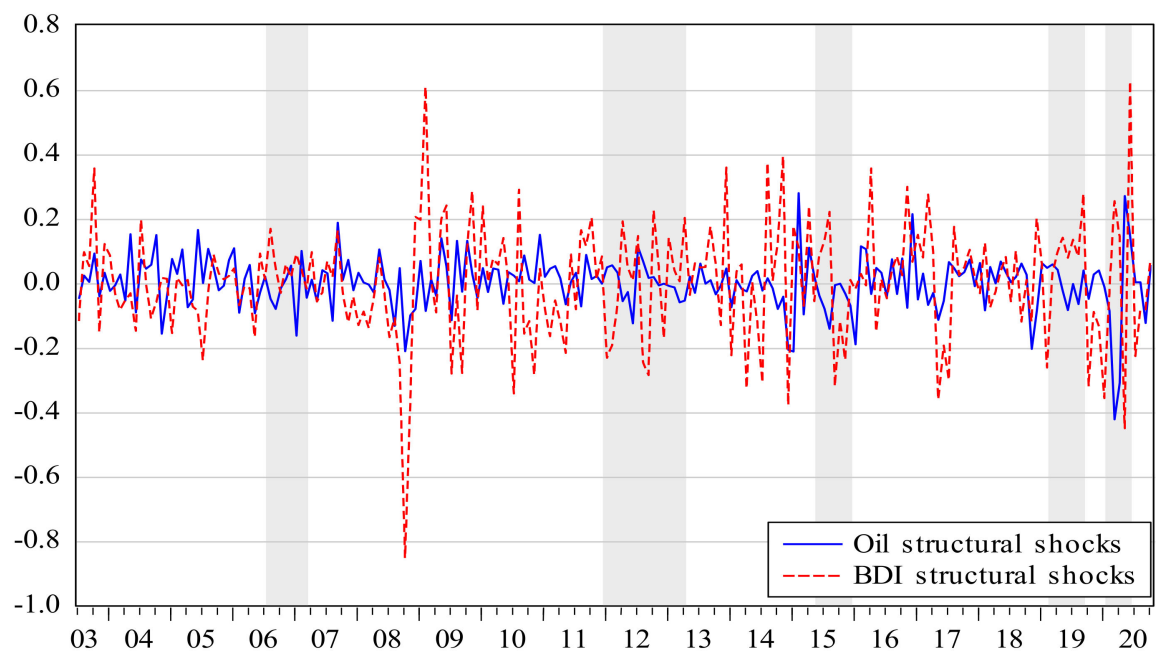

Figure 3. Dynamic characteristics identification of oil commodity attribute. Note: There is a negative relationship between the demand and the structural impact of crude oil price shown in shadow parts.

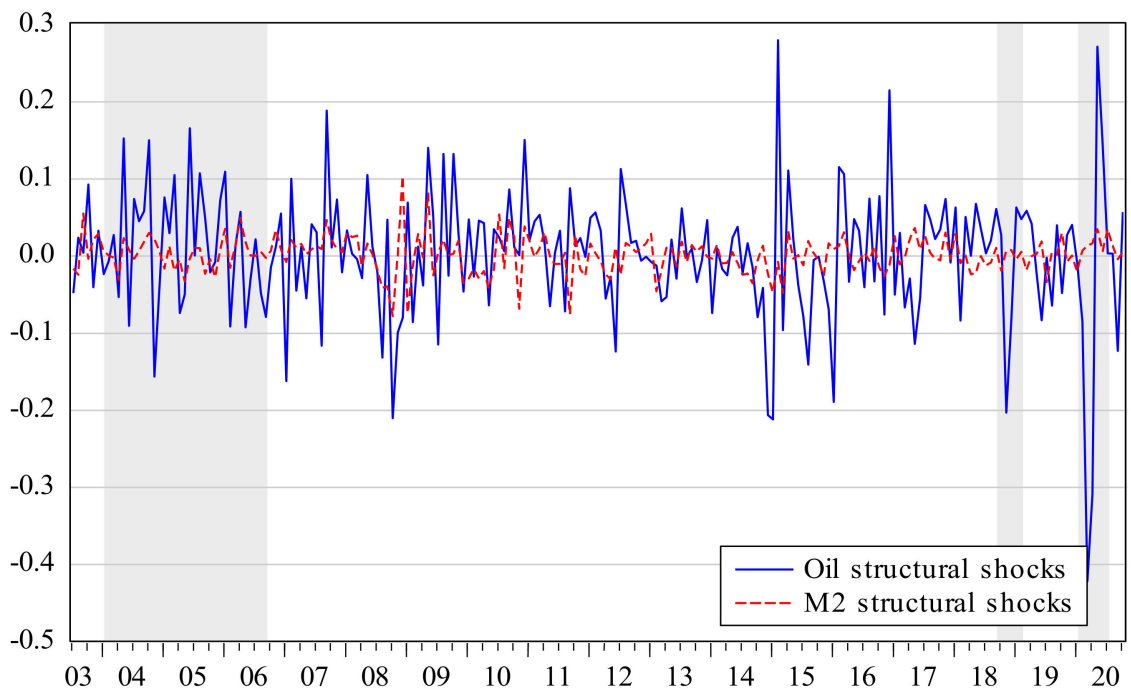

Figure 4. Dynamic characteristics identification of oil financial attribute. Note: There is a negative relationship between the monetary policy and the structural impact crude oil price, shown in shadow parts.

The dominant stages of oil financial attribute and commodity attribute are different, and there are joint domination periods. Table 1 shows that the dominant periods of oil financial attributes are mostly before and after special events. Specifically, the oil financial attribute dominates six stages of 2006.9-2007.3, 2007.7-2007.12, 2011.12-2013.4, 2015.5-2015.12, 2019.2-2019.9 and 2020.7-later. The period that oil commodity attribute dominates is the stable period of the international crude oil market, including 2003.7-2006.9, 2007.3-2007.6, 2013.4-2015.5 and 2016.1-2019.2. At the same time, the time period in which the dual attributes of oil jointly dominate the international crude oil market price is related to special events: 2008.1-2011.12 and 2020.1-2020.7.

Since the second half of 2006, countries around the world have gradually established commodity markets and improved their market systems. Because of the negative relationship between commodities like crude oil and financial assets such as stocks, a growing 
number of investors use crude oil as a hedge to secure their own expectations or excess profits $[53,54]$. Investors can further obtain relevant information of the international crude oil market through monetary policy changes. At this time, the price changes of the international crude oil market are mainly dominated by the financial attribute of oil. However, Since the uncertainty of profits in the financial market is higher than the expected profits from investment in the real economy, and the international crude oil market gradually adjusts the price fluctuations caused by the financialization of the commodity market, the international oil price gradually stabilizes and is regulated by the market supply and demand relationship. Therefore, the commodity attribute of oil dominated from March to June 2007. In addition, since July 2020, affected by the global epidemic and the residual effect of the implementation of sanctions against Iran by developed countries such as the United States, the price of the international crude oil market is under pressure to recover. From the perspective of market stability and investor sentiment, policymakers use relevant policy tools to adjust the price of the international crude oil market, gradually improve the confidence of market participants, and then achieve the effect of stabilizing the market.

Table 1. Stage characteristics dominated by dual attributes of oil.

\begin{tabular}{|c|c|c|c|c|}
\hline Attribute & Specific Period & $\begin{array}{c}\text { Maximum } \\
\text { Duration }\end{array}$ & $\begin{array}{l}\text { Minimum } \\
\text { Duration }\end{array}$ & $\begin{array}{l}\text { Proportion of } \\
\text { Period }\end{array}$ \\
\hline $\begin{array}{l}\text { Commodity attribute } \\
\text { dominates }\end{array}$ & $\begin{array}{c}\text { 2003.7-2006.8; 2007.3-2007.6; 2013.4-2015.5; } \\
\text { 2016.1-2019.2 }\end{array}$ & 38 & April & $51 \%$ \\
\hline $\begin{array}{c}\text { Financial attribute } \\
\text { dominates }\end{array}$ & $\begin{array}{l}\text { 2006.9-2007.2; 2007.7-2007.12; 2012.1-2013.3; } \\
\quad \text { 2015.6-2015.12; 2019.3-2019.9; 2020.7- }\end{array}$ & 15 March & May & $23 \%$ \\
\hline Jointly dominate & 2008.1-2011.12; 20190-2020.7.1 & 48 & October & $26 \%$ \\
\hline
\end{tabular}

The dynamic characteristics of the dominant stages of the two attributes of oil are mainly related to the external environment. As the financialization of commodity markets deepens, more and more investors trade crude oil as a financial asset. A large amount of capital flows into the international crude oil market to further expand its degree of financialization, thus promoting the development of the oil industry in the direction of financialization [38]. Affected by capital flows, investor expectations and speculative activities, international crude oil market prices mainly reflect the speculative will of oil investment groups. At this time, because the profit of the financial market is greater than that of the real investment, in order to pursue the expected profit or excess profit, the enterprise will change its capital allocation between finance and entity, and then the commodity attribute of oil becomes weak, and the financial attribute of oil will dominate. However, the uncertainty of profits in the financial market will make the commodity attribute of oil dominate. The international crude oil market has a regulating effect on the speculative manipulation of oil investment groups, and the investment of enterprises in the financial market will bear higher risks, which increases the uncertainty of enterprises to obtain expected profits. The change of external environment, such as economic development, technological progress and industrial structure adjustment, makes enterprises change their investment strategy. The macroeconomic improvement expands the profit space of the enterprise to invest in the real economy, and the consumption demand of oil is bound to rise; otherwise, the consumption demand of oil will be reduced. The financial attribute of oil plays a major role in price discovery in the international crude oil market. On the contrary, hedging and speculative arbitrage are obviously inadequate. The influence of monetary policy on the price of the international crude oil market is mainly reflected in changing the demand for oil consumption [50]. At this time, the commodity attribute of oil dominates.

The joint action of two attributes of oil is highly related to special events. From 2008 to 2011 , the global financial crisis caused by the subprime mortgage crisis in the United States and the European debt crisis first impacted the stability of the financial market. Due to the development of economic and financial integration, the impact gradually spilled 
into the commodity market and affected the smooth operation of the economy. Countries use policy tools such as monetary policies to maintain the confidence of investors in the market and the smooth operation of the economy to stimulate consumers demand and minimize the impact of the crisis on the market [55]. Early in 2020, the outbreak of the COVID-19 epidemic posed new challenges to the effectiveness of the global health system. Affected by the epidemic, countries have taken different attitudes and measures to reduce the impact [56]. As a result of the development of global integration, the epidemic began to spread around the world, further affecting international links such as shipping and air transportation, and ultimately affecting the development of the global economy. This effect undoubtedly creates pressure for global economic recovery. Because of the high dependence of economic development on oil and other energy sources, the international crude oil market price is impacted by oil demand. Meanwhile, the epidemic also affects the exchange of information and expectations of market participants, so the price of the international crude oil market can also be influenced by monetary policy. Therefore, the change of international crude oil price is dominated by both oil financial attributes and commodity attributes. To sum up, Hypothesis 1 and 2 holds.

There are differences in the duration characteristics of the two oil attributes. Table 1 also reports the statistical characteristics of the duration of two oil attributes. According to Table 1 , both the maximum duration and minimum duration of international oil price jointly dominated by the two attributes of oil are the largest, which are 48 months and 7 months, respectively. The maximum duration of oil commodity attribute dominating international crude oil price is 38 months, being greater than that of oil financial attribute, which is 16 months; however, the minimum duration of oil financial attribute is greater than that of oil commodity attribute, which are 5 months and 4 months respectively. By comparing the proportion of dominant time of different attributes in the sample period, it is found that the international crude oil market price is mainly influenced by oil commodity attribute, accounting for $51 \%$. The second is the jointly dominant time of the two attributes of oil on the international oil price, accounting for $26 \%$. The least is the dominant time of oil's financial attribute, accounting for $23 \%$. Combined with the above analysis, it can be seen that the impact of special events on the international crude oil market lasts the longest, and the ability of the market to deal with special events is still a key indicator to test the stability of the market [10]. As oil is the most important input factor, the price change of the international crude oil market is still affected by the market supply and demand relationship, especially the change of demand to a large extent. However, the impact of the financial attribute of oil on the international oil price has gradually developed into a factor that cannot be ignored in the market.

\section{Risk Measurement Methods of International Crude Oil Market}

The dual attributes of oil significantly affect the risk evolution of the international crude oil market. With the development of oil commodity attributes and financial attributes, the price of the international crude oil market is more vulnerable to the influence of external policy environment, market supply and demand relationship and investor attention, and the degree of price fluctuation is gradually expanded $[9,10]$. Therefore, the regulation of international crude oil market risks helps to improve market stability and protect investors rights and interests. In addition, the accurate selection of risk measurement methods is helpful to improve investment benefit and market supervision efficiency. If the risk of the international crude oil market is not measured correctly, it may be overestimated or underestimated, which will lead to the change of capital level in the international crude oil market, and then affect the capital allocation of investors. Market participants transfer investment activities to markets with low risk levels. According to the existing literature, the specific definition of risks in the international crude oil market refers to the maximum loss that the investment in crude oil assets may suffer under the normal fluctuation of the international crude oil market; further, according to the statistical language, it refers to $\alpha$ in this paper, i.e., the probability of the maximum possible loss of international 
crude oil returns in a certain period of time. In addition, under different returns trends of the international crude oil market, there are differences in investors' expectations and attention in the international crude oil market. Based on the above analysis, this paper defines the risks of rising and falling returns in the international crude oil market in Equations (4) and (5).

$$
\begin{gathered}
\mathrm{P}\left(\mathrm{R}_{\Delta \mathrm{t}}<\text { URisk }\right)=1-\alpha \\
\mathrm{P}\left(\mathrm{R}_{\Delta \mathrm{t}}<- \text { DRisk }\right)=\alpha
\end{gathered}
$$

where $\Delta t$ represents a specific time period; $R_{\Delta t}$ represents the international crude oil market returns in a specific time period; $\alpha$ is the confidence level; URisk and DRisk represent the risks of the international crude oil market when returns rise and fall respectively.

The CAViaR model is used to measure the risks of the international crude oil market. The existing risk measurement methods are mainly based on different properties of the international crude oil market returns. On the one hand, the market risk is measured from the perspective of heteroscedasticity of asset returns, such as in literature which uses static and dynamic VaR based on GARCH models to predict risks in financial markets like stock markets, international crude oil markets and virtual money markets [20-22]. On the other hand, from the perspective of asset returns agglomeration to measure market risks. The extreme value theory is used to measure risks in most existing literature. ES mainly forecasts financial market risks from the perspective of extreme events to make up for the characteristics that ordinary VaR cannot capture. The above-mentioned methods have two common features. One is based on the specific distribution of international crude oil market returns. The second is based on the method of parameter estimation. For the former method, international oil market returns are often limited to certain specific distributions, Such as normal distribution, $t$ distribution and GED distribution. For the latter method, parameter models are used to measure international crude oil market risks, and the accuracy of parameter estimation and the fitting degree of the model become two aspects to be considered in model construction. It can be seen from the definition of risks that the measurement of international crude oil market risk is actually a prediction of quantile. Based on this, the agglomeration effect of international crude oil market returns and the application of quantile regression in risk measurement are comprehensively considered. Engle and Manganeli [29] proposed a conditional auto-regressive value at risk model (CAViaR) which does not need to assume the distribution of international crude oil market returns. At the same time, considering the agglomeration of international crude oil market risk, the model adds the lag term of the risk. By using four forms of the CAViaR model, referring to existing literature $[15,31,32,57]$, this paper measures the risk of the international crude oil market.

The basic form of the CAViaR model is shown in Equation (6).

$$
\operatorname{Risk}_{t}(\boldsymbol{\beta})=\beta_{1}+\sum_{i=1}^{q} \beta_{i} \operatorname{Risk}_{t-i}(\boldsymbol{\beta})+\sum_{j=1}^{r} \beta_{j} l\left(\boldsymbol{R}_{t-j}\right)
$$

where Risk $_{t}$ refers to the international crude oil market risk in month $t ; l\left(\boldsymbol{R}_{t-j}\right)$ is an exogenous variable function, which mainly describes the influence of different forms of international crude oil market returns on risks. The lag term $\operatorname{Risk}_{t-i}(\boldsymbol{\beta})$ describes the agglomeration of international crude oil market risks. Engle and Manganeli [29] further proposed four model forms, namely, the absolute symmetry model, the asymmetric model, the indirect GARCH model and the adaptive model based on different forms of international crude oil market returns, as in Equations (7)-(10).

Absolute symmetry model:

$$
\operatorname{Risk}_{t}(\boldsymbol{\beta})=\beta_{1}+\beta_{2} \operatorname{Risk}_{t-1}(\boldsymbol{\beta})+\beta_{3}\left|R_{t-1}\right|
$$


Asymmetric models:

$$
\operatorname{Risk}_{t}(\boldsymbol{\beta})=\beta_{1}+\beta_{2} \operatorname{Risk}_{t-1}(\boldsymbol{\beta})+\beta_{3}\left(R_{t-1}\right)^{+}+\beta_{4}\left(R_{t-1}\right)^{-}
$$

where $\left(R_{t-1}\right)^{+}=\max \left(R_{t-1}, 0\right)$ and $\left(R_{t-1}\right)^{-}=\min \left(R_{t-1}, 0\right)$ depict the positive and negative monthly returns of the international crude oil market.

Indirect GARCH $(1,1)$ Model:

$$
\operatorname{Risk}_{t}(\boldsymbol{\beta})=\left(\beta_{1}+\beta_{2} \operatorname{Risk}_{t-1}^{2}(\beta)+\beta_{3} R_{t-1}^{2}\right)^{1 / 2}
$$

Adaptive models:

$$
\operatorname{Risk}_{t}\left(\beta_{1}\right)=\operatorname{Risk}_{t-1}\left(\beta_{1}\right)+\beta_{1}\left\{\left[1+\exp \left(G\left[R_{t-1}-\operatorname{Risk}_{t-1}\left(\beta_{1}\right)\right]\right)\right]^{-1}-\alpha\right\}
$$

where $G$ is a finite positive integer. When the returns exceed the risk value, it is necessary to increase the value of $G$ appropriately; on the contrary, it is necessary to reduce the value of $G$ appropriately. Only in this way can the goodness of fit of the adaptive model be increased. Based on this, this paper mainly constructs a suitable CAViaR model from the first three models to measure the international crude oil market risk.

The test of the model fitting effect is to compare the risk fitting situation of different risk measurement methods to the international crude oil market. This paper uses the values of statistics HIT and DQ put forward by Engle and Manganeli [29], on the basis of the properties of VaR and dynamic quantile test. HIT mainly examines the difference between returns and risk measurement results. The representation of HIT test statistics is shown in Equation (11).

$$
\operatorname{Hit}_{t}(\boldsymbol{\beta})=I\left(R_{t}<\operatorname{Risk}_{t}(\boldsymbol{\beta})\right)-\alpha .
$$

where $I(\Delta)$ is an indicative function. When $R_{t}<\operatorname{Risk}_{t}(\boldsymbol{\beta})$, the value of $\operatorname{Hit}_{t}(\boldsymbol{\beta})$ is $1-\alpha$; otherwise, the value is $-\alpha$. In addition, according to the definition of quantile function, the value of $\operatorname{Hit}_{t}(\boldsymbol{\beta})$ is 0 when the sample is given T-1 period data. In other words, the value of $\operatorname{Hit}_{t}(\boldsymbol{\beta})$ has nothing to do with the risk and the term lag of the international crude oil market, hence the use of the HIT test may not be sufficient to test the goodnessof-fit of the model. Further, Engle and Manganeli [29] proposed the DQ test, including fitting sample and test sample. A statistical representation of a DQ test is shown in Equations (12) and (13).

$$
\begin{gathered}
D Q_{I S}=\frac{H i t^{\prime}(\hat{\boldsymbol{\beta}}) X(\hat{\boldsymbol{\beta}})\left(\hat{M}_{T} \hat{M}_{T}^{\prime}\right)-X^{\prime}(\hat{\boldsymbol{\beta}}) H i t^{\prime}(\hat{\boldsymbol{\beta}})}{\alpha(1-\alpha)} \sim \chi_{q}^{2} . \\
D Q_{O S}=N_{R}^{-1} H i t^{\prime}\left(\hat{\boldsymbol{\beta}_{T_{R}}}\right) X\left(\hat{\boldsymbol{\beta}_{T_{R}}}\right)\left[X^{\prime}\left(\hat{\boldsymbol{\beta}_{T_{R}}}\right) X\left(\hat{\boldsymbol{\beta}_{T_{R}}}\right)\right]^{-1} \\
\quad \times X^{\prime}\left(\hat{\boldsymbol{\beta}_{T_{R}}}\right) H i t^{\prime}\left(\hat{\boldsymbol{\beta}_{T_{R}}}\right) / \alpha(1-\alpha) \sim \chi_{q}^{2} \text { as } R \rightarrow \infty .
\end{gathered}
$$

where $D Q_{I S}$ and $D Q_{O S}$ respectively refer to the DQ test statistics of the fitting sample and the test sample; $X(\hat{\beta})$ and $\hat{\beta}$ are related, which are used to measure the information of international crude oil market returns in the fitting sample, i.e., $\operatorname{Hit}(\hat{\boldsymbol{\beta}})=$ $\left[\operatorname{Hit}_{1}(\hat{\boldsymbol{\beta}}), \ldots, \operatorname{Hit}_{T}(\hat{\boldsymbol{\beta}})\right]^{\prime}$. In the same way, assuming $T_{R}$ represents the sample data of the fitting sample, $N_{R}$ represents the sample data of the test sample. $X\left(\hat{\beta_{T_{R}}}\right)$ and $\hat{\beta_{T_{R}}}$ are related, $\mathrm{n}=T_{R}+1, \ldots, T_{R}+N_{R}$, and they are used to measure the information of international crude oil market returns in the test sample, i.e., $\hat{M}_{T}=X^{\prime}(\hat{\boldsymbol{\beta}})-$ $\left\{\left(\left(2 T \hat{c_{T}}\right)^{-1} \sum_{t=1}^{T} I\left(\left|R_{t}<\operatorname{Risk}_{t}(\hat{\boldsymbol{\beta}})\right|<\hat{c_{T}}\right) \times X^{\prime}(\hat{\boldsymbol{\beta}}) \nabla \operatorname{Risk}_{t}(\hat{\boldsymbol{\beta}})\right\} \times \hat{D_{T}^{-1}} \nabla^{\prime} \operatorname{Risk}_{t}(\hat{\boldsymbol{\beta}})\right.$. 


\section{Asymmetric Risk Characteristics of International Crude Oil Market under the Condition of Returns Heterogeneity}

The two attributes of oil play a key role in the risk evolution of the international crude oil market, and investors' expectation is another key factor in the risk evolution. In the context of different returns trends of the international crude oil market, the investors' expectations and attention are different. Based on this, this paper further compares and analyzes the evolution characteristics of risks when the international crude oil market returns rise and fall with the asymmetric model (8), according to the definition and measure methods of risks in the third Section (the model fitting results can be requested from the author). Figure 5 shows the evolution of international crude oil market risks under the condition of returns heterogeneity, and Table 2 reports the numerical characteristics.

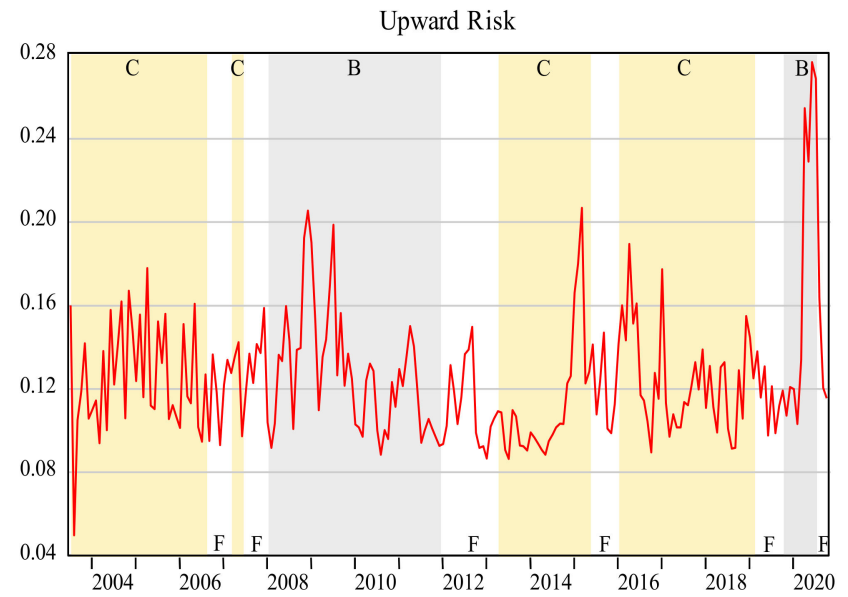

(a)

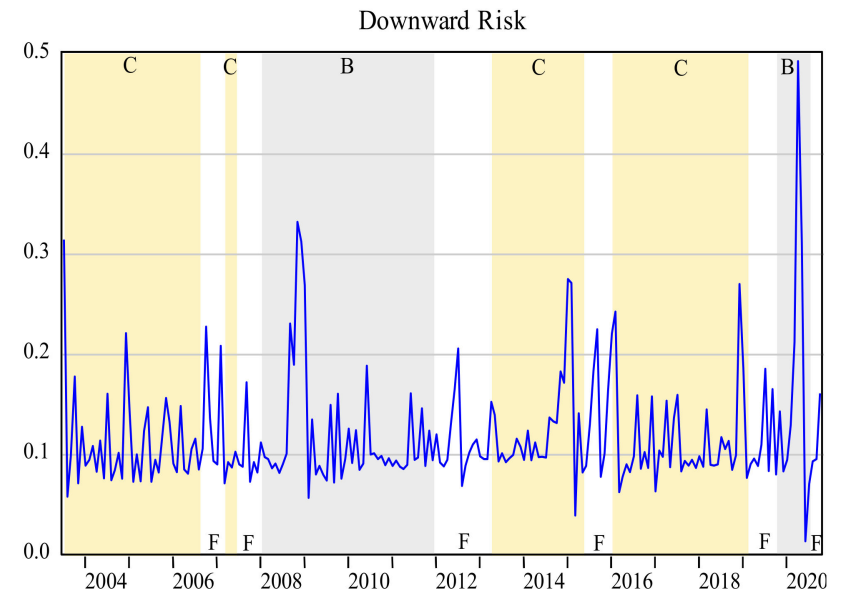

(b)

Figure 5. The risk evolution of the international crude oil market under the condition of returns rise and fall. Note:(a) displays the risk evolution under the rising returns in the international crude oil market; (b) shows the risk evolution under the falling returns in the international crude oil market. B is the period jointly dominated by two attributes of oil; $\mathrm{C}$ is the period dominated by oil commodity attribute; $\mathrm{F}$ is the period dominated by oil finance attribute.

Table 2. Descriptive analysis of risk evolution in international crude oil market under different returns trends.

\begin{tabular}{|c|c|c|c|c|c|}
\hline \multicolumn{6}{|c|}{ (a) Risk of Rising Returns in International Crude Oil Markets } \\
\hline & Mean & Median & Maximum value & Minimum value & Standard deviation \\
\hline Full sample & 0.0712 & 0.0592 & 0.5114 & 0.0003 & 0.0687 \\
\hline Commodity attribute dominates & 0.0628 & 0.0527 & 0.2499 & 0.0004 & 0.0528 \\
\hline Financial attribute dominates & 0.0624 & 0.0667 & 0.1729 & 0.0003 & 0.0449 \\
\hline Dual attributes jointly dominate & 0.0943 & 0.0675 & 0.5114 & 0.0013 & 0.1003 \\
\hline \multicolumn{6}{|c|}{ (b) Risk of Falling Returns in International Crude Oil Market } \\
\hline Full sample & 0.1181 & 0.0958 & 0.4916 & 0.0122 & 0.0582 \\
\hline Commodity attribute dominates & 0.1149 & 0.0972 & 0.3134 & 0.0376 & 0.0489 \\
\hline Financial attribute dominates & 0.1151 & 0.0942 & 0.2262 & 0.0671 & 0.0430 \\
\hline Dual attributes jointly dominate & 0.1265 & 0.0941 & 0.4916 & 0.0122 & 0.0811 \\
\hline
\end{tabular}

The distribution of international crude oil market risk is asymmetric, and the influences of oil attributes on different trend risks are different. Figure 5a shows the risk evolution under the trend of rising returns in the international crude oil market, and Figure $5 \mathrm{~b}$ shows the risk evolution under the trend of falling returns in the international crude oil market. By comparing Figure $5 a, b$, it can be seen that the risk under the falling returns trend in the international crude oil market is greater than that under the trend of rising returns in the whole sample period, which indicates that the distribution of risks in the international crude oil market is asymmetric. In addition, the risk evolution under 
the trend of rising returns in the international crude oil market shows a cyclical change in different attribute-dominated periods, which increases first and then decreases or decreases first and then increases, while the risk evolution characteristics are related to the attributes of oil. Specifically, when the two attributes of oil are jointly dominant, the range of risk changes is the largest, and the range of fluctuation shows a trend of expansion; the smallest range of risk changes is during the dominant period of oil financial attribute; when the oil financial attribute dominates, the risk variation range is the least. When the oil commodity attribute is dominant, the risk fluctuation amplitude of the international crude oil market has no consistent characteristics.

Different attention of investors determines the asymmetric role of oil attributes in different returns trends $[14,58]$. Market participants are more concerned about falling returns than rising returns. When the international crude oil market returns rise, investors will not blindly follow up, but rationally obtain other market information and formulate trading strategies through the grasp of information and their own judgment. At this time, the international crude oil market plays a major role, and factors such as supply and demand relationship and speculative demand in the market can be controlled to a certain extent. Therefore, the risks show cyclical changes. The decline in international crude oil market returns will cause market panic, and market participants' expectations will decline. At this time, "copycat trading" will occur in the international crude oil market, leading to the decline of market capital level. Due to the ability of market participants to obtain market information and the asymmetry of information, some investors have a certain lag when making investment strategies. Based on this, the change of trading strategy will ultimately affect the stability of the international crude oil market, thus increase market risks [9]. Therefore, the risk under the trend of falling returns in the international crude oil market changes greatly in different dominant periods of different attributes of oil

There is significant asymmetry in the instantaneous effect of different oil attributes on the risk of international crude oil market with different returns trends. The alternation of dominant periods indicates the instantaneous effect of different oil attributes on the risk evolution of international crude oil market. The alternation of the dominant position of oil commodity attribute and financial attribute will cause the risk under rising returns in the international crude oil market to a great extent, while the alternation of the dominant positions of oil dual-attribute and oil financial attribute exerts different effects on the risk under the rise and fall of returns in the international crude oil market. From the perspective of the risk of falling returns in the international crude oil market, we can see that in September 2006, the dominant position of the oil commodity attribute alternated to that of the financial attribute, and international crude oil market risks suddenly increased. In March 2007, the dominant position of oil financial attribute alternated to that of commodity attribute, and the international crude oil market risks had no big fluctuation. The same phenomenon occurred in the subsequent several alternate dominant periods of oil commodity attribute and financial attribute. In addition, the risk evolution is related to events when the dominant position of oil financial attribute and commodity attribute alternates. The alternation of dominant position between oil financial attribute and the dual attribute occurred in January 2008 and December 2011, which does not make the risks of the international crude oil market fluctuate greatly. Meanwhile, in October 2019 and July 2020, the dominant position of oil financial attribute and that of the dual attributes alternated again, but this alternation makes the international crude oil market risk fluctuates greatly.

Changes in market information factors lead to differences in this instantaneous effect [12]. The financial attribute of oil attracts a large number of institutional investors and speculative groups into the international crude oil market, increasing the complexity of market participants. Compared to the oil commodity attribute, the complexity of market participants is higher when the oil financial attribute is dominant [39,44]. Because of the difference in the ability of different participants to obtain information and the asymmetry of information between different participants, institutional investors and speculative groups can withdraw from the market in a timely manner before returns fall or price trends change. 
These trading strategies reduce the capital level of the international crude oil market, and then change the stability of the international crude oil market. The risk evolution phenomenon of the dominant position of oil financial attribute alternating to that of commodity attribute is mainly related to the effectiveness of the international crude oil market. The effectiveness of the international crude oil market reflects the timeliness of price and risk response when uncertainty factors increase in the market. In markets where institutional investors and speculative groups are involved, the effectiveness of the international crude oil market is relatively low, and there is a lag in the response to uncertainties in the market, so in the short term, the change from oil financial attribute domination to the commodity attribute domination will not cause the risk fluctuation of the international crude oil market. There are differences in the impact of major events on the international crude oil market, and the risk evolution is inconsistent when the dominant position alternates from the dual attributes of oil to the financial attribute [58]. In 2008, the financial crisis caused by the subprime mortgage crisis in the United States ultimately affected the global economy. The global outbreak of the COVID-19 epidemic in 2020 highlights the key role of the health system in all aspects of financial stability, economic development and people's lives. Compared to the financial crisis, the global epidemic outbreak has had a greater impact on the international crude oil market. Therefore, the recovery of the market needs greater efforts. As the epidemic abates, countries and regions around the world dedicate to pushing their economies forward and stimulating people's consumption. However, due to the large impact of the epidemic and the possibility of recurrence, the expectation of participants in the international crude oil market was reduced and the market risk was increased eventually.

Moreover, investors' attention and sentiment are vulnerable to the instantaneous effect of oil dual attributes and financial attribute $[10,58]$. When the dominant positions of oil commodity attribute and financial attribute alternate with each other, due to the change of market fundamental information, investors' judgment on the market is not very different when the returns rise or fall. Therefore, the effect of the alternation between the dominant positions of two oil attributes on the risk under the rising and falling returns in the international crude oil market is consistent. The joint domination of oil dual attributes is related to major events, and the judgment of market participants on the evolution of major events and the fundamental information judgment of the international crude oil market are asymmetric $[14,58]$. Participants with strong information acquisition ability will formulate corresponding trading strategies in advance to deal with the decline in international crude oil market returns, but when the returns rise, investors' rational behavior and low attention to events will not cause a wide range of changes in the risk under the rising returns in the international crude oil market.

The joint effect of oil dual attributes on the risks under rising and falling returns in the international crude oil market is significantly higher than that of a single attribute of oil, and this effect is mainly reflected in the characteristics of risk changes. Table 2a,b report descriptive analysis of the risks under rising and falling returns in the international crude oil market, respectively. According to the average risk of the international crude oil market under different returns trends, it can be seen that different attributes of oil have the same effect on the risk under rising and falling returns. Specifically, no matter the risk of the international crude oil market is due to rising or falling returns, the role of oil dual attributes on risks is greater than that of oil single attribute on risks. The span of risk evolution mainly depends on the difference between the mean value and standard deviation of the international crude oil market under different trends. From the point of view of the difference of the mean value, based on the dominant position of different attributes of oil, when the dual attributes of oil dominate and the returns rise, the average value of risks is maximum, and the minimum occurs when the oil financial attribute dominates. The difference between the maximum and minimum is 0.0315 . When the returns fall, the difference between the maximum and minimum risks average values is 0.0116. In terms of the standard deviation between the risk under rising returns and that 
under falling returns, when the two attributes of oil jointly dominate and the returns rise, the standard deviation of the risks reach maximum, and the minimum occurs when the oil financial attribute dominates, and the difference between the two is 0.0554 . While during the returns falling period, the difference between the maximum and the minimum risk standard deviation is 0.0381 .

Differences in investors' attention to market information are the main factors of the heterogeneity of the effects of different oil attributes [14,31]. The cyclical evolution of the risk under rising returns indicates that market participants will integrate the fundamental information of the international crude oil market, such as the total market demand, including the speculative demand, the total social demand and the market trading volume, in order to improve the efficiency of capital allocation and expected returns when making trading strategies [12]. Different investment strategies increase the uncertainty of the international crude oil market, and finally increase the risk of the international crude oil market. Therefore, investors pay more attention to the risk evolution when returns fall $[9,51]$. The periodic evolution of the risk under rising returns will inevitably experience extreme change from peak to trough or from trough to peak. The risk of falling returns in the international crude oil market basically revolves around 0.1 , and influenced by different attributes of oil, it may have a mutation. Therefore, compared to the risk under falling returns, the risk under rising returns in the international crude oil market has a larger mean difference and higher fluctuation difference. With the development of financial and economic integration, the impact of major events on financial stability and economic development will quickly spread to the international crude oil market $[10,30,31]$. Under the domination of oil dual attributes, the complexity of market participants lowers the market effectiveness, leading to the increase of uncertainties in the market and the decrease of the stability of the international crude oil market, which ultimately leads to greater changes in the risk of the international crude oil market. Therefore, when the dual attributes of oil dominate, the international crude oil market risk changes the most. By analyzing the statistical characteristics of different attributes of oil on the risks of the international crude oil market, it is helpful to reduce the risk and fluctuation of the international crude oil market, and to improve the efficiency of investment and capital allocation.

\section{Conclusions}

The heterogeneity of investor sentiment and the dual attributes of oil are the key factors that cause the asymmetry of risk in the international crude oil market. This paper uses the monthly data from April 2003 to October 2020 to identify the dynamic characteristics of oil's commodity attribute and financial attribute, and analyzes the asymmetric characteristics of risk evolution and risk degree in the international crude oil market under the condition of oil returns heterogeneity. The conclusions are as follows:

The dominant position alternation between two oil attributes has a significant asymmetric influence on the risk evolution of the international crude oil market. When returns are rising in the international crude oil market, in the dominant period of different oil attributes, the risk shows a cyclical change of first rising and then falling or first falling and then rising. In addition, the dominant position alternation of oil commodity attribute and financial attribute will cause the risk under rising returns in the international crude oil market to change to a greater extent. When the returns are falling in the international crude oil market, and when the dominant position of oil commodity attribute changes to that of the finance attribute, the risk suddenly increases; while there is no great fluctuation of the risk, when the dominant position of oil financial attribute changes to that of the commodity attribute. Similarly, the impact of the two alternations between oil dual attributes domination and financial attribute domination on the risk of the international crude oil market when returns rise and fall is related to the market effect of major events.

There is asymmetry in the impact of oil attributes on the risks of the international crude oil market under different returns trends. Through the analysis of the numerical characteristics of the risk in the international crude oil market under the condition of 
returns heterogeneity, it is found that the average value of the risk under the trend of falling returns is greater than that under the rising returns, and the degree of risk change is just the opposite. In different dominant periods of different attributes of oil, when the dual attributes of oil dominate, as well as the return rise, the average value of risks is maximum, and the minimum occurs when the oil financial attribute dominates. The difference between the maximum and minimum is 0.0315 . When the returns fall, the difference between the maximum and minimum risks average values is 0.0116 . In terms of the standard deviation between the risk under rising returns and that under falling returns, when the two attributes of oil jointly dominate, as well as the returns rise, the standard deviation of the risks reach maximum, and the minimum occurs when the oil financial attribute dominates, and the difference between the two is 0.0554 . While during the returns falling period, the difference between the maximum and the minimum risk standard deviation is 0.0381 .

Based on the above conclusions, this paper puts forward the following policy recommendations. One is to strengthen the identification mechanism of the dominant periods of different oil attributes, which is helpful to monitor the fluctuation source of the international crude oil market and guard against risk shocks. Second, the establishment of an early warning mechanism for major events is necessary. On the one hand, the instantaneous effect of the alternation of the dominant periods between two single attributes on international crude oil market risk is less than that of the alternation between dual attributes and a single attribute; on the other hand, the abrupt effect of risk evolution characteristics of international crude oil market before major events can be controlled beforehand. By establishing an early warning mechanism for major events, we can effectively protect the legitimate rights and interests of investors and prevent and resolve the impact of the international crude oil market on the commodity market, financial market and macroeconomic steady development. Third, attention should be paid to the risk shock of the international crude oil market under the trend of returns falling as well as that under the trend of rising returns.

Author Contributions: Conceptualization, Y.L., Y.Y and H.D.; methodology, Z.L. and H.D; software, Z.L and H.D.; validation, Y.L., Z.L., Y.Y and H.D.; formal analysis, Y.L., Z.L., Y.Y and H.D.; investigation, Y.L., Z.L., Y.Y and H.D.; resources, Z.L. and H.D.; data curation, Y.L., Z.L. and H.D.; writing-original draft preparation, Y.L., Z.L and H.D.; writing—review and editing, H.D.; visualization, H.D.; supervision, Y.L., Z.L. and Y.Y.; project administration, Y.L. and Z.L.; funding acquisition, Z.L. and Y.Y. All authors have read and agreed to the published version of the manuscript.

Funding: This research was funded by Hunan Provincial Department of Education, grant number 19A103.

Institutional Review Board Statement: Not applicable.

Informed Consent Statement: Not applicable.

Data Availability Statement: The data are available upon request.

Conflicts of Interest: The authors declare no conflict of interest.

\section{Appendix A. Preliminary Test of the SVAR Model}

Granger causality test results of Brent, BDI and GM2 are shown in Table A1. Granger causality test is used to test causality between variables as well as the short-term constraint matrix. As the test shows, The $p$ values of Brent and BDI are less than 0.05 , indicating that there is a two-way causality between the international crude oil market price and the dry bulk freight index. In addition, GM2 is the Granger cause of Brent, while international crude oil price will not cause changes in the money supply. The causality test between BDI and GM2 indicates that when the null hypothesis is "GM2 is not the Granger cause of BDI", the statistical and p-value of the test are 15.729 and 0.0000 , respectively; instead, when the null hypothesis is "BDI is not the Granger cause of GM2", the p-value is 0.8165, thus accepting the null hypothesis. Based on this, the money supply is the Granger cause of the dry bulk freight index, but the dry bulk freight index will not cause money supply 
changes. Therefore, there is a correlation among Brent, BDI and GM2, and the short-term constraint matrix meets the expected setting.

Table A1. Granger causality test.

\begin{tabular}{cccc}
\hline Variable Correlation & Null Hypothesis & F Statistics & Prob. \\
\hline \multirow{2}{*}{ Brent and BDI } & BDI is not the Granger cause of Brent & 3.0646 & 0.0488 \\
& Brent is not the Granger cause of BDI & 6.1687 & 0.0025 \\
\hline \multirow{2}{*}{ Brent and GM2 } & GM2 is not the Granger cause of Brent & 5.3865 & 0.0053 \\
& Brent is not the Granger cause of GM2 & 0.3657 & 0.6942 \\
\hline \multirow{2}{*}{ BDI and GM2 } & GM2is not the Granger cause of BDI & 15.729 & 0.0000 \\
& BDI is not the Granger cause of GM2 & 0.2028 & 0.8165 \\
\hline
\end{tabular}

The model test mainly includes two aspects: stationary test and lag order determination. VAR series models require variables to be stationary variables. This paper uses the ADF method to test the stationarity of international crude oil price, i.e., Brent, BDI and GM2. In the process of the ADF test, it is necessary to determine whether there are intercept terms and trend terms for different variables. For variables that are differential, based on the sequence diagram of three variables, there are intercept and trend items in Brent, BDI and GM2, and there is no intercept term and trend term after variable difference. The results of the test are shown in Table A2. Considering the length, this paper only shows the test results after variable difference. According to the test results, The ADF test statistics of Brent, BDI and GM2 after difference are $-10.62,-12.04$ and -14.05 , and the $p$-value is $0.0000<0.05$. Therefore, all variables are stationary after the first order difference.

Table A2. Results of stationary tests for variables.

\begin{tabular}{cccccc}
\hline \multirow{2}{*}{ Variable } & \multicolumn{3}{c}{ ADF Critical Value } & \multirow{2}{*}{ ADF Value } & \multirow{2}{*}{ Prob. } \\
\cline { 2 - 4 } & $\mathbf{1 \%}$ Critical Value & $\mathbf{5 \%}$ Critical Value & $\mathbf{1 0 \%}$ Critical Value & & 0.0000 \\
Brent & -2.5760 & -1.9423 & -1.6157 & -10.619 & 0.0000 \\
BDI & -2.5760 & -1.9423 & -1.6157 & -12.039 & 0.0000 \\
GM2 & -2.5760 & -1.9423 & -1.6157 & -14.049 & 0 \\
\hline
\end{tabular}

Note: considering the length of the paper, the Table A2 only shows the test results after the difference of variables.

The SC criterion is used for the selection of lag orders. AIC and SC are commonly used criteria for determining lag orders. AIC is the criterion of model fitting, and SC has a strict test procedure. The basic idea of the SC criterion test is to determine the appropriate lag length by comparing the goodness of fit of VAR models with different lag orders. The main test process is as follows: Lags of Brent, BDI and GM2 variables are added to the VAR model periodically until SC value is no longer reduced, that is, the lag order $p$ that makes SC value reach the minimum is selected. The selection result of lag order is shown in Table A3. It can be known from the SC minimum criterion that when $p=1$, the value of $\mathrm{SC}$ is the minimum. Based on this, the SVAR(1) model is fitted in this paper.

Table A3. Lag order selection.

\begin{tabular}{ccccccc}
\hline Lag & LogL & LR & FPE & AIC & SC & HQ \\
\hline 0 & 716.210 & NA & $2.04 \times 10^{-7}$ & -6.891 & -6.843 & -6.871 \\
1 & 743.774 & 54.063 & $1.71 \times 10^{-7}$ & -7.071 & $-6.877^{*}$ & $-6.992^{*}$ \\
2 & 755.463 & 22.587 & $1.66 \times 10^{-7}$ & -7.096 & -6.758 & -6.959 \\
3 & 765.688 & $19.461^{*}$ & $1.64 \times 10^{-7} *$ & $-7.108^{*}$ & -6.625 & -6.912 \\
\hline
\end{tabular}




\section{References}

1. Adekunle, W.; Bagudo, A.M.; Odumosu, M.; Inuolaji, S.B. Predicting stock returns using crude oil prices: A firm level analysis of Nigeria's oil and gas sector. Resour. Policy 2020, 68. [CrossRef]

2. Asai, M.; Gupta, R.; McAleer, M. Forecasting volatility and co-volatility of crude oil and gold futures: Effects of leverage, jumps, spillovers, and geopolitical risks. Int. J. Forecast. 2020, 36, 933-948. [CrossRef]

3. Chkir, I.; Guesmi, K.; Ben Brayek, A.; Naoui, K. Modelling the nonlinear relationship between oil prices, stock markets, and exchange rates in oil-exporting and oil-importing countries. Res. Int. Bus. Financ. 2020, 54. [CrossRef]

4. Li, Z.H.; Zhong, J.H. Impact of economic policy uncertainty shocks on China's financial conditions. Eur. J. Oper. Res. 2020, 35. [CrossRef]

5. Huynh TL, D.; Burggraf, T.; Nasir, M.A. Financialisation of natural resources \& instability caused by risk transfer in commodity markets. Resour. Policy 2020, 66. [CrossRef]

6. Latunde, T.; Akinola, L.S.; Dare, D.D. Analysis of capital asset pricing model on Deutsche bank energy commodity. Green Financ. 2020, 2, 20-34. [CrossRef]

7. Palao, F.; Pardo, A.; Roig, M. Is the leadership of the Brent-WTI threatened by China's new crude oil futures market? J. Asian Econ. 2020, 70, 8. [CrossRef]

8. D'Ecclesia, R.L.; Magrini, E.; Montalbano, P.; Triulzi, U. Understanding recent oil price dynamics: A novel empirical approach Energy Econ. 2014, 46, S11-S17. [CrossRef]

9. Liao, G.K.; Li, Z.H.; Du, Z.Q.; Liu, Y. The heterogeneous interconnections between supply or demand side and oil risks. Energies 2019, 12, 2226. [CrossRef]

10. Liu, Y.; Dong, H.; Failler, P. The Oil Market Reactions to OPEC's Announcements. Energies 2019, 12, 3238. [CrossRef]

11. Saculsan, P.; Kanamura, T. Examining risk and return profiles of renewable energy investment in developing countries: The Case of the Philippines. Green Financ. 2019, 2, 135-150. [CrossRef]

12. Ji, Q.; Liu, B.Y.; Fan, Y. Risk dependence of CoVaR and structural change between oil prices and exchange rates: A time-varying copula model. Energy Econ. 2019, 77, 80-92. [CrossRef]

13. Ballco, P.; Gracia, A. Do market prices correspond with consumer demands? Combining market valuation and consumer utility for extra virgin olive oil quality attributes in a traditional producing country. J. Retail. Consum. Serv. 2020, 53, 11. [CrossRef]

14. Dong, H.; Liu, Y.; Chang, J.Q. The heterogeneous linkage of economic policy uncertainty and oil return risks. Green Financ. 2019, 1, 46-66. [CrossRef]

15. Liu, K.; Luo, C.Q.; Li, Z. Investigating the risk spillover from crude oil market to BRICS stock markets based on Copula-POTCoVaR models. Quant. Financ. Econ. 2019, 3, 754-771. [CrossRef]

16. Zhong, J.H.; Wang, M.D.; Drakeford, B.; Li, T.H. Spillover effects between oil and natural gas prices: Evidence from emerging and developed markets. Green Financ. 2019, 1, 30-45. [CrossRef]

17. Roh, T.Y.; Tourani-Rad, A.; Xu, Y.H.; Zhao, Y. Volatility-of-volatility risk in the crude oil market. J. Futures Mark. 2021, 41, 245-265. [CrossRef]

18. Cui, Z.Y.; Kirkby, J.L.; Nguyen, D. A data-driven framework for consistent financial valuation and risk measurement. Eur. J. Oper. Res. 2021, 289, 381-398. [CrossRef]

19. Cabedo, J.D.; Moya, I. Estimating oil price 'value at risk' using the historical simulation approach. Energy Econ. 2003, 25, 239-253. [CrossRef]

20. Bernardi, M.; Catania, L. Comparison of value-at-risk models using the MCS approach. Comput. Stat. 2016, 31, 579-608. [CrossRef]

21. Ferraty, F.; Quintela-del-Rio, A. Conditional VAR and expected shortfall: A new functional approach. Economet. Rev. 2016, 35, 263-292. [CrossRef]

22. Gkillas, K.; Katsiampa, P. An application of extreme value theory to cryptocurrencies. Econ. Lett. 2018, 164, 109-111. [CrossRef]

23. Li, T.H.; Zhong, J.H.; Huang, Z.M. Potential dependence of financial cycles between emerging and developed countries: Based on ARIMA-GARCH copula model. Emerg. Mark. Financ. Trade 2020, 56, 1237-1250. [CrossRef]

24. Li, Z.H.; Dong, H.; Huang, Z.H.; Failler, P. Asymmetric effects on risks of Virtual Financial Assets (VFAs) in different regimes: A case of bitcoin. Quant. Financ. Econ. 2018, 2, 860-883. [CrossRef]

25. Longin, F.M. The asymptotic distribution of extreme stock market returns. J. Bus. 1996, 69, 383-408. [CrossRef]

26. Zhao, L.T.; Liu, K.; Duan, X.L.; Li, M.F. Oil price risk evaluation using a novel hybrid model based on time-varying long memory. Energ. Econ. 2019, 81, 70-78. [CrossRef]

27. Yang, L.; Hamori, S. Forecasts of Value-at-Risk and Expected Shortfall in the Crude Oil Market: A Wavelet-Based Semiparametric Approach. Energies 2020, 13, 3700. [CrossRef]

28. Valenti, D.; Manera, M.; Sbuelz, A. Interpreting the oil risk premium: Do oil price shocks matter? Energ. Econ. 2020, 91. [CrossRef]

29. Engle, R.F.; Manganelli, S. CAViaR: Conditional autoregressive value at risk by regression quantiles. J. Bus. Econ. Stat. 2004, 22, 367-381. [CrossRef]

30. Li, Z.H.; Wang, Y.; Huang, Z.H. Risk connectedness heterogeneity in the cryptocurrency markets. Front. Phys. 2020, 8. [CrossRef]

31. Li, Z.H.; Dong, H.; Floros, C.; Charemis, A.; Failler, P. Re-examining bitcoin volatility: A CAViaR-based approach. Emerg. Mark. Financ. Trade 2021, 1-19. [CrossRef]

32. Meng, X.C.; Taylor, J.W. An approximate long-memory range-based approach for value at risk estimation. Int. J. Forecast. 2018, 34, 377-388. [CrossRef] 
33. Youssef, M.; Belkacem, L.; Mokni, K. Value-at-Risk estimation of energy commodities: A long-memory GARCH-EVT approach. Energy Econ. 2015, 51, 99-110. [CrossRef]

34. Jeon, J.; Taylor, J.W. Using CAViaR Models with Implied Volatility for Value-at-Risk Estimation. J. Forecast. 2013, 32, 62-74. [CrossRef]

35. Drakos, A.A.; Kouretas, G.P.; Zarangas, L. Predicting conditional autoregressive value-at-risk for stock markets during tranquil and turbulent periods. J. Financ. Risk Manag. 2015, 4, 168. [CrossRef]

36. Qureshi, K. Value-at-Risk: The effect of autoregression in a quantile process. arXiv 2016, arXiv:1605.04940.

37. Wen, D.; Liu, L.; Ma, C.; Wang, Y. Extreme risk spillovers between crude oil prices and the U.S. exchange rate: Evidence from oil-exporting and oil-importing countries. Energy 2020, 212. [CrossRef]

38. Zhang, Y.J.; Chevallier, J.; Guesmi, K. "De-financialization" of commodities? Evidence from stock, crude oil and natural gas markets. Energy Econ. 2017, 68, 228-239. [CrossRef]

39. Raheem, I.D.; Bello, A.K.; Agboola, Y.H. A new insight into oil price-inflation nexus. Resour. Policy 2020, 68, 9. [CrossRef]

40. Chen, H.T.; Liu, L.; Wang, Y.D.; Zhu, Y.M. Oil price shocks and US dollar exchange rates. Energy 2016, 112, 1036-1048. [CrossRef]

41. Wen, F.H.; Xiao, J.H.; Huang, C.X.; Xia, X.H. Interaction between oil and US dollar exchange rate: Nonlinear causality, time-varying influence and structural breaks in volatility. Appl. Econ. 2018, 50, 319-334. [CrossRef]

42. Naz, M.; Iftikhar, S.F.; Fatima, A. Does financial inclusiveness matter for the formal financial inflows? Evidence from Pakistan. Quant. Financ. Econ. 2020, 4, 19-35. [CrossRef]

43. Chen, L.M.; Du, Z.Q.; Tan, Y. Sustainable exchange rates in China: Is there the heterogeneous effect of economic policy uncertainty. Green Financ. 2019, 1, 346-363. [CrossRef]

44. Sukharev, O.S.; Voronchikhina, E.N. Financial and non-financial investments: Comparative econometric analysis of the impact on economic dynamics. Quant. Financ. Econ. 2020, 4, 382-411. [CrossRef]

45. Tang, K.; Xiong, W. Index Investment and the Financialization of Commodities. Financ. Anal. J. 2012, 68, 54-74. [CrossRef]

46. Ghassan, H.B.; AlHajhoj, H.R. Long run dynamic volatilities between OPEC and non-OPEC crude oil prices. Appl. Energy 2016, 169, 384-394. [CrossRef]

47. Kisswani, K.M. Does OPEC act as a cartel? Empirical investigation of coordination behavior. Energy Policy 2016, 97, 171-180. [CrossRef]

48. Loutia, A.; Mellios, C.; Andriosopoulos, K. Do OPEC announcements influence oil prices? Energy Policy 2016, 90, 262-272. [CrossRef]

49. Baumeister, C.; Kilian, L. Forecasting the real price of oil in a changing world: A forecast combination approach. J. Bus. Econ. Stat. 2015, 33, 338-351. [CrossRef]

50. Bloch, H.; Rafiq, S.; Salim, R. Economic growth with coal, oil and renewable energy consumption in China: Prospects for fuel substitution. J. Int. Financ. Mark. Inst. Money 2015, 44, 104-115. [CrossRef]

51. Kilian, L. Not all oil price shocks are alike: Disentangling demand and supply shocks in the crude oil market. Am. Econ. Rev. 2009, 99, 1053-1069. [CrossRef]

52. Dong, H.; Chen, L.M.; Zhang, X.Y.; Failler, P.; Xu, S. The Asymmetric Effect of Volatility Spillover in Global Virtual Financial Asset Markets: The Case of Bitcoin. Emerg. Mark. Financ. Trade 2020, 56, 1293-1311. [CrossRef]

53. Benkraiem, R.; Lahiani, A.; Miloudi, A.; Shahbaz, M. New insights into the US stock market reactions to energy price shocks. $J$. Int. Financ. Mark. Inst. Money 2018, 56, 169-187. [CrossRef]

54. Bouri, E. Return and volatility linkages between oil prices and the Lebanese stock market in crisis periods. Energy 2015, 89, 365-371. [CrossRef]

55. Chen, S.L.; Ouyang, S.Y.; Dong, H. Oil price pass-through into consumer and producer prices with monetary policy in china: Are there non-linear and mediating effects. Front. Energy Res. 2020, 8, 35. [CrossRef]

56. Jeris, S.S.; Nath, R.D. Covid-19, oil price and UK economic policy uncertainty: Evidence from the ARDL approach. Quant. Financ. Econ. 2020, 4, 503-514. [CrossRef]

57. Li, Z.H.; Liao, G.K.; Albitar, K. Does corporate environmental responsibility engagement affect firm value? The mediating role of corporate innovation. Bus. Strateg. Environ. 2020, 29, 1045-1055. [CrossRef]

58. Li, Z.H.; Chen, L.M.; Dong, H. What are bitcoin market reactions to its-related events? Int. Rev. Econ. Financ. 2021, 73, 1-10. [CrossRef] 